\title{
C4-bound imidazolylidenes: from curiosities to high-impact carbene ligands
}

\author{
Martin Albrecht*
}

This feature article summarizes the progress achieved thus far in using C4-bound imidazolylidenes as a new class of ligands for transition metals. Since the discovery of this unusual carbene bonding mode in 2001, various rational routes towards complexes containing C4-bound carbenes have evolved. These advances allowed for studying the impact of this new type of ligand on the transition metal center, both from a fundamental point of view as well as from a more applied perspective, in particular for catalytic applications. The promising results accomplished in this relatively short period of time demonstrate the potential of C4-bound imidazolylidenes as unique carbene ligands for inducing catalytic activity and for mediating unprecedented transformations.

\section{Introduction}

The discovery of $\mathrm{N}$-heterocyclic carbenes (NHCs) as ligands for transition metals has spurred the development of a number of research areas in materials science. Efforts have led to new components for light-emitting diodes ${ }^{1}$ and electronic devices, ${ }^{2}$ though the most significant advances so far have been achieved undoubtedly in the development of new catalyst systems. ${ }^{3}$ In many cases, metal-NHC systems provided extraordinary high catalytic activity, often surpassing the ubiquitous phosphine analogues in homogeneous transformations. The high performance of NHC complexes has been generally attributed to the strong NHC-metal bond and to the high donor ability of carbene ligands. Most obvious improvements have been achieved in olefin metathesis ${ }^{4}$ and cross-coupling reactions, ${ }^{5}$

Department of Chemistry, University of Fribourg, Chemin du Musee 9,CH-1700 Fribourg, Switzerland.E-mail:martin.albrecht@unifr.ch; Fax: + 41 263009738; Tel: + 41263008786

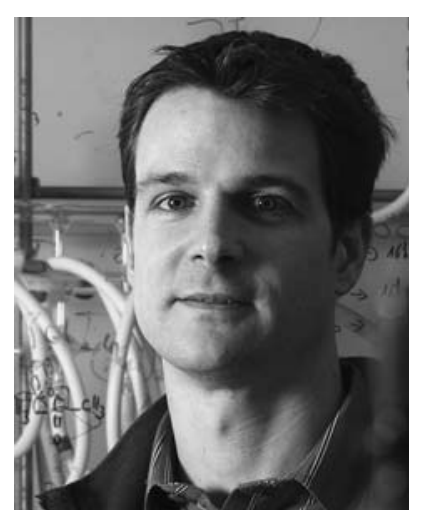

Martin Albrecht studied chemistry at the University of Bern (Switzerland) and obtained his PhD under the supervision of Prof. Gerard van Koten from Utrecht University (The Netherlands) in 2000. After postdoctoral studies with Robert H. Crabtree (Yale) and with Ciba SC (Basel, Switzerland), he moved to the University of Fribourg as the first Alfred Werner Assistant Professor. His research interests are in (bio)organometallic chemistry in general, with special emphasis on developing novel carbene ligands for catalytic and electronic applications. He has recently received a prestigious Starting Grant from the European Research Council for further exploring this chemistry. and in many cases, new and unprecedented catalytic reactions have been disclosed. ${ }^{6}$

Imidazolium-derived NHC ligands typically coordinate to the metal center via the $\mathrm{C} 2$ carbon (Scheme 1). Only recently, coordination via $\mathrm{C} 4$ has been identified as another bonding mode of such carbenes. ${ }^{7}$ This bonding mode provides access to a new type of NHC ligands in which the heteroatoms are not located in $\alpha, \alpha^{\prime}$ position but in $\alpha, \beta^{\prime}$ position with respect to the metal-bound carbon. As a consequence, no canonical resonance form of the carbene can be drawn without introducing additional charges. Therefore, C4-bound carbenes are often referred to as 'abnormal' carbenes. ${ }^{8}$ Scheme 2 depicts the most relevant limiting resonance structures of both $\mathrm{C} 2$ - and C4-bound carbene complexes. These basic considerations suggest that the zwitterionic form of C4-bound carbenes has a larger contribution to the overall binding mode than in classical C2-bound carbenes. Despite this, the term carbene is preserved, in particular due to the isomeric relationship between C2- and C4-bound imidazolylidene ligands. Similar
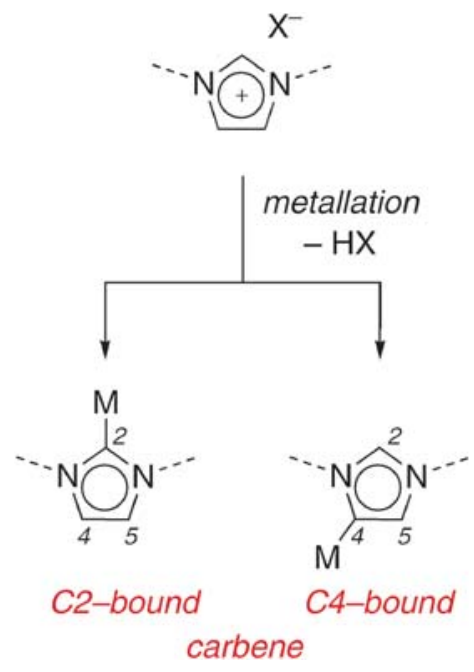

Scheme 1 


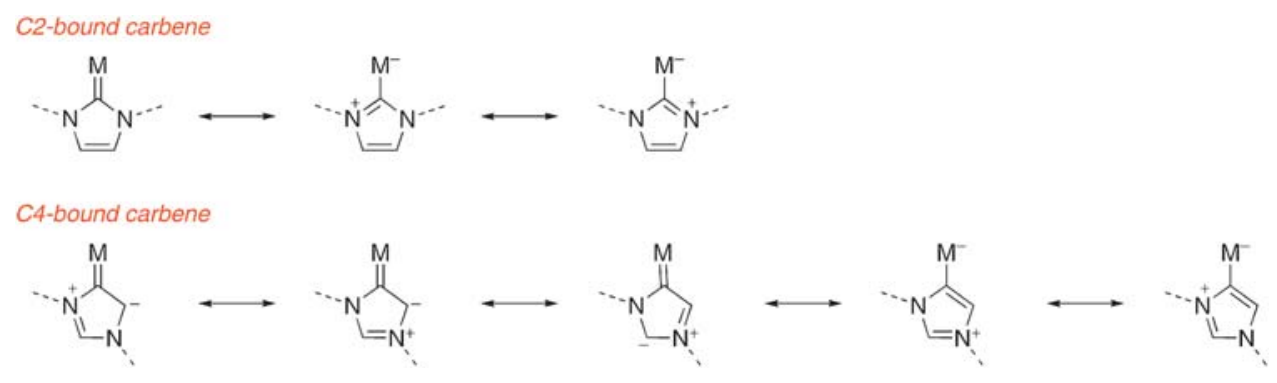

Scheme 2

arguments also apply for carbenes derived from different $\mathrm{N}$-heterocyclic precursors such as 2-, 3- and 4-pyridylidenes. ${ }^{9}$

\section{Metallation}

Similar to other carbenes that lack extensive heteroatom stabilization, ${ }^{10}$ free $\mathrm{C} 4$ carbenes display low stability and are considerably less stable than their crystallographically characterized $\mathrm{C} 2$ counterparts. ${ }^{11}$ This is a direct consequence of the different arrangement of the heteroatoms, which are considered to be crucial for stabilizing the carbene via resonance and inductive carbon-heteroatom interactions. Energy decomposition analyses of the tautomers $\mathbf{A}$ and $\mathbf{B}$ of imidazole predict that the $\mathrm{C} 2$ carbene $\mathbf{A}$ is about $80 \mathrm{~kJ} \mathrm{~mol}^{-1}$ more stable than the $\mathrm{C} 4$ carbene $\mathbf{B}$ (Scheme 3). ${ }^{12}$

Similarly, calculation of the acidity constants for the different protons of the imidazolium cation revealed $\mathrm{p} K_{\mathrm{a}}$ values of 7.0, 24.9 and 33.0 for the N-bound hydrogen, the C2-bound hydrogen (i.e. formation of $\mathbf{A}$ ), and $\mathrm{C} 4-\mathrm{H}$ (formation of $\mathbf{B}$ ), respectively (Scheme 3). ${ }^{13}$ These values indicate a substantially higher barrier for $\mathrm{C} 4$ than for $\mathrm{C} 2$ metallation of imidazolium salts via $\mathrm{C}-\mathrm{H}$ bond activation.

The theoretical results have recently been challenged by a number of experimental investigations. For example, $N, N^{\prime}$-dialkylated carbenes of type A exchange the carbonbound protons very easily. Deuterium incorporation has been accomplished within few minutes by exposure of the carbene to dmso- $d_{6}$ or to $\mathrm{CD}_{3} \mathrm{OD} .{ }^{14}$ Exchange under such mild conditions is remarkable and indicates a considerable lability of these protons. Notably, the corresponding imidazolium salt is resistant towards such isotope exchange reactions. A different study showed that chlorination of the $\mathrm{C} 4$ and $\mathrm{C} 5$ position in $\mathrm{C} 2$ carbenes can be achieved under mild conditions using $\mathrm{CCl}_{4}$ in THF. ${ }^{15}$

The lability of the $\mathrm{C} 4-\mathrm{H}$ bond in free $\mathrm{C} 2$ carbenes has indeed been used for the formation of C4-bound metal complexes (Scheme 4) ${ }^{16}$ The final product corresponds to a formal rearrangement of a free $\mathrm{C} 2$ carbene to a metallated $\mathrm{C} 4$-bound carbene. While the continuously increasing number of complexes obtained via this route ${ }^{16}$ indicates a potential utility of

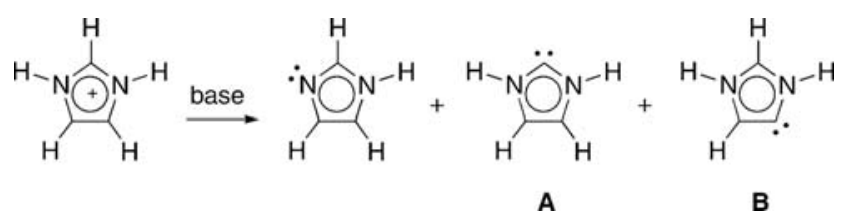

Scheme 3

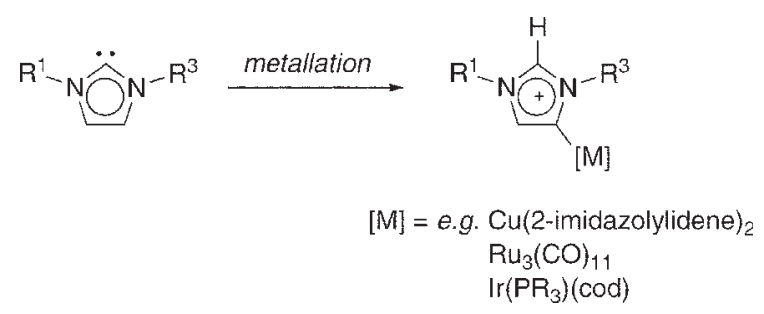

Scheme 4

this method, only little mechanistic details for this rearrangement have been uncovered thus far. In some cases, C4 metallation via free $\mathrm{C} 2$ carbene formation has been rationalized by steric factors, e.g. due to the presence of bulky substituents $\left(\mathrm{R}^{1}=\mathrm{R}^{3}=t \mathrm{Bu}\right){ }^{16 d}$ In other cases, this carbene rearrangement occurs by coincidence rather than being the product of a designed reaction trajectory. In order to become a synthetically useful metallation method, the driving forces for the rearrangement need to be unraveled. Perhaps, isotope labeling experiments would assist in determining whether the formal 1,3-shift of the proton is an intramolecular process or whether solvent molecules or metals mediate $\mathrm{C}-\mathrm{H}$ bond making and breaking. Irrespective of the underlying mechanism, such a C2-to-C4 rearrangement of the carbene suggests that the two tautomers $\mathbf{A}$ and $\mathbf{B}$ are energetically perhaps less separated than predicted by calculations.

A variety of more reliable methods for synthesizing C4-bound carbene complexes have been developed during the last few years. These methods are briefly discussed below and follow up a more descriptive review that appeared recently. ${ }^{17}$

\section{Metallation via $\mathrm{C} 4-\mathrm{H}$ bond activation}

Given the higher acidity of the C2-bound proton in imidazolium systems, $\mathrm{C} 4-\mathrm{H}$ activation generally requires protection of the $\mathrm{C} 2$ position. This has been accomplished by substituting the proton by an alkyl or an aryl group prior to metallation. A number of 2-alkylated and 2-arylated imidazoles are commercially available and provide a fast access to this chemistry. Substitution effectively blocks the $\mathrm{C} 2$ position and directs metallation to the $\mathrm{C} 4$ position. $\dagger$ This approach, developed by Crabtree and co-workers, has been extended by us and others for preparing different complexes containing C4-bound

$\uparrow$ For reasons of consistency, the atom numbering of Scheme 1 is preserved throughout the entire article and the metal-bound carbon is referred to as $\mathrm{C} 4$ carbon, even though the metal-bound carbon actually constitutes the $\mathrm{C} 2, \mathrm{C} 3$ or $\mathrm{C} 5$ carbon depending on the substituents at the nitrogen atoms and the location of annelated rings. 

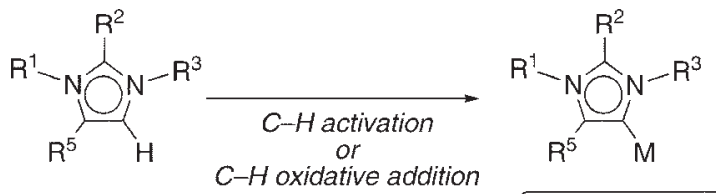

$R^{1}, R^{2}, R^{3}=$ alkyl, aryl

$R^{5}=H$, alkyl, aryl

Scheme 5

mono- ${ }^{18-21}$ and dicarbene ${ }^{22-25}$ ligands. Metallation has been reported to occur predominantly via $\mathrm{C}-\mathrm{H}$ bond activation ${ }^{19-25}$ though oxidative $\mathrm{C}-\mathrm{H}$ bond addition is viable as well (Scheme 5). ${ }^{18}$

When the substitutents $\mathrm{R}^{1}$ and $\mathrm{R}^{3}$ at the nitrogen heteroatoms are different, $\mathrm{C} 4$ - and $\mathrm{C} 5$-metallation becomes distinguishable $\left(\mathrm{R}^{5}=\mathrm{H}\right)$ and can lead to the formation of isomeric product mixtures. ${ }^{18}$ Regioselective metallation may be induced by incorporation of chelating donor substituents at one of the nitrogen substituents. ${ }^{18,21-24}$

It should be noted, however, that alkylation of the C2 position is not always a reliable method and under certain conditions, side reactions may become dominant. For example, metallation of the imidazolium salt 1 with $\operatorname{Ag}_{2} \mathrm{O}$ and subsequent transmetallation produced the C2-bound carbene complex 2 (Scheme 6, cod $=1,5$-cyclooctadiene) ${ }^{26}$ Thorough analysis of this apparent $\mathrm{C}\left(\mathrm{sp}^{2}\right)-\mathrm{C}\left(\mathrm{sp}^{3}\right)$ bond activation revealed remarkable mechanistic details. Carbon-carbon bond cleavage is silver(I)-mediated and proceeds via a stepwise oxidation of the methyl substituent at the $\mathrm{C} 2$ position to a formyl group (C) with concomitant silver reduction. The carbonyl group is cleaved readily ${ }^{27}$ in the presence of water, formed during the oxidation of $\mathbf{1}$, and another equivalent of $\mathrm{Ag}^{+}$ions to give the normal C2-bound silver-bis(carbene) intermediate D. While the proposed intermediates $\mathbf{C}$ and $\mathbf{D}$ have not been detected directly, closely related species have been isolated and support this mechanism. For example, a similar reactivity has been observed with 2-benzylated imidazolium salts, leading to the formation of benzoic acid as easily detectable side product. Hence, $n$-alkyl and benzyl groups attached to $\mathrm{C} 2$ may be unsafe as blocking groups when using $\mathrm{Ag}_{2} \mathrm{O}$ for metallation. Phenyl or isopropyl groups appeared to be inert and may be more appropriate for transmetallation

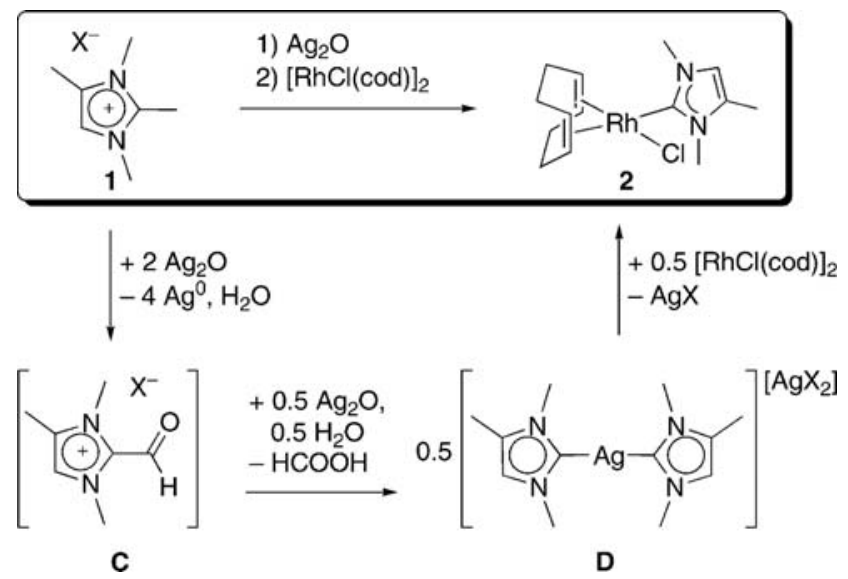

Scheme 6

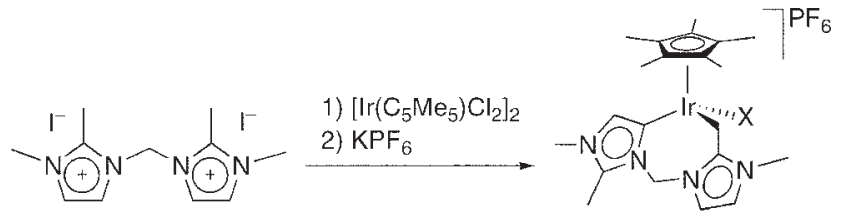

3a

Scheme 7

protocols involving $\mathrm{Ag}$ (carbene) complexes as NHC transfer agents.

Related C-H bond activation of the supposedly protective methyl group attached to the $\mathrm{C} 2$ carbon has been noted when the diimidazolium salt 3a was metallated with $\left[\operatorname{Ir}\left(\mathrm{cp}^{*}\right) \mathrm{Cl}_{2}\right]_{2}$ (Scheme 7, $\mathrm{cp}^{*}=\mathrm{C}_{5} \mathrm{Me}_{5}=$ pentamethylcyclopentadienyl) ${ }^{28}$ Such $\mathrm{C}\left(\mathrm{sp}^{3}\right)-\mathrm{H}$ bond activation and formation of complexes similar to $\mathbf{4}$ has been suppressed, at least in part, by connecting the two imidazolium sites via an ethylene rather than a methylene linker, thus increasing the flexibility and the distance between the two donor moieties.

In contrast, metallation of the diimidazolium salts $\mathbf{3}$ with $\left[\mathrm{Pd}(\mathrm{OAc})_{2}\right]$ or with a suitable rhodium precursor proceeded without noticeable interference with the methyl group attached to $\mathrm{C} 2$ and afforded complexes $\mathbf{5}$ and $\mathbf{6}$, respectively (Scheme 8). ${ }^{23,24}$ While in rhodium chemistry, isolated yields of the metallated complexes are only moderate and do not allow definite conclusions to be drawn, palladation proceeds in yields above $90 \%$. This indicates that side reactions as mentioned above are of very low relevance. Moreover, the reaction conditions typically used for palladation of 2-alkylated diimidazolium ligand precursors are remarkably similar to those developed for $2 \mathrm{H}$-diimidazolium salts. ${ }^{29}$ This again indicates that the kinetic barrier for the $\mathrm{C}-\mathrm{H}$ bond activation is not substantially different for $\mathrm{C} 2$ and for $\mathrm{C} 4$ metallation. ${ }^{30}$ Based on these results, we successfully expanded this metallation protocol recently also to platinum chemistry. ${ }^{25}$ These results illustrate the potential of this $\mathrm{C} 4-\mathrm{H}$ bond activation methodology for preparing a broad range of transition metal complexes containing C4-bound carbene ligands.

In some cases, protection of the $\mathrm{C} 2$ position is not necessary. When using the iridium polyhydride precursor $\left[\mathrm{IrH}_{5}\left(\mathrm{PPh}_{3}\right)_{2}\right]^{31}$

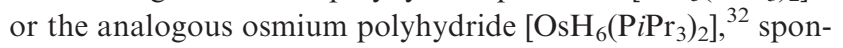
taneous metallation at the $\mathrm{C} 4$ position takes place also with

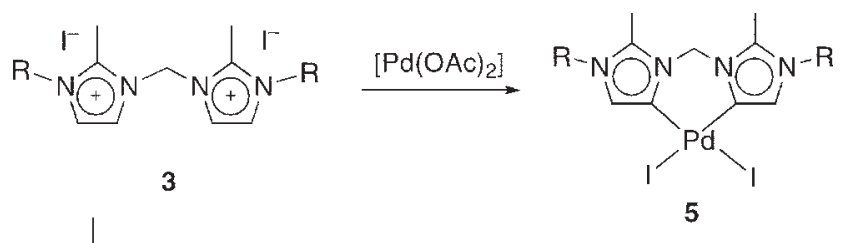

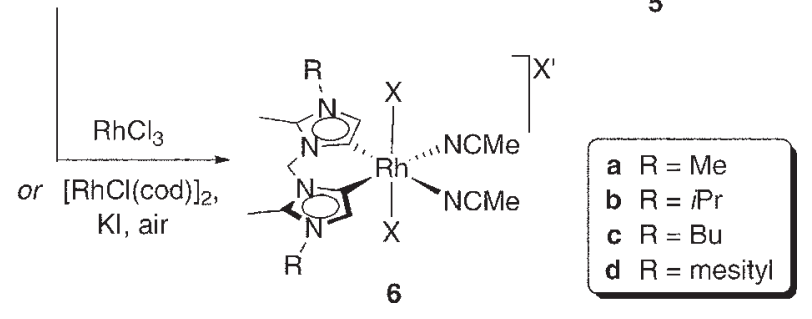

Scheme 8 


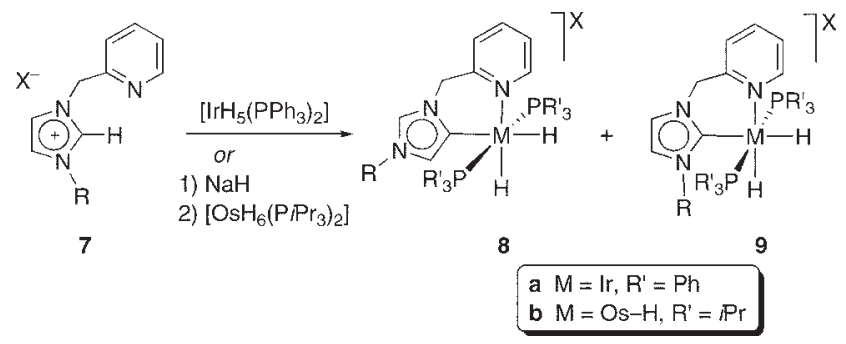

Scheme 9

Table 1 C4 vs. C2 iridation of 7 as a function of counteranion $\mathrm{X}^{-}$and substituent R (Scheme 9)

\begin{tabular}{lll}
\hline $\mathrm{R}$ & $\mathrm{X}$ & $\begin{array}{l}\text { Product } \\
\text { ratio } \mathbf{8 a}: \mathbf{9 a}\end{array}$ \\
\hline $\mathrm{Me}$ & $\mathrm{Br}$ & $9: 91$ \\
$\mathrm{Me}$ & $\mathrm{OAc}_{\mathrm{Bac}}$ & $20: 80$ \\
$\mathrm{Me}$ & $\mathrm{BF}_{4}$ & $45: 55$ \\
$\mathrm{Me}$ & $\mathrm{PF}_{6}$ & $50: 50$ \\
$\mathrm{Me}$ & $\mathrm{SbF}_{6}$ & $89: 11$ \\
$i \mathrm{Pr}$ & $\mathrm{Br}^{\mathrm{Pr}}$ & $16: 84$ \\
$i \mathrm{Pr}$ & $\mathrm{BF}_{4}$ & $100: 0$ \\
\hline
\end{tabular}

$2 \mathrm{H}$-imidazolium salts such as 7. Variations in the imidazolium precursor, in particular modification of the nitrogen substituent $\mathrm{R}$ and the counteranion $\mathrm{X}^{-}$revealed a delicate balance between $\mathrm{C} 2$ and $\mathrm{C} 4$ metallation (Scheme 9, Table 1).

Sterically demanding substituents at nitrogen $(\mathrm{R}=$ mesityl, $i \mathrm{Pr}$ ) induce predominantly $\mathrm{C} 4$ metallation due to spatial interference between the substituent $\mathrm{R}$ and the metal-bound phosphine $\mathrm{PR}_{3}^{\prime}{ }_{3}{ }^{32}$ Smaller substituents $(\mathrm{R}=\mathrm{Me}$, benzyl) lack this discrimination and favor product formation originating from $\mathrm{C} 2-\mathrm{H}$ (but apparently not from $\mathrm{C} 5-\mathrm{H}$ ) bond activation. In addition, different pathways have been suggested for the activation of $\mathrm{C} 2-\mathrm{H}$ and the $\mathrm{C} 4-\mathrm{H}$ bonds. These pathways are critically dependent on the nature of the counteranion $\mathrm{X}^{-}$of the imidazolium salt. It has been proposed that the $\mathrm{C} 2-\mathrm{H}$ bond is cleaved heterolytically, while $\mathrm{C} 4-\mathrm{H}$ bond activation has been calculated to proceed via an oxidative addition pathway. ${ }^{31}$ Heterolytic bond cleavage will be favored with small and coordinating anions that can engage in hydrogen bonding, thus assisting in polarized bond scission. By contrast, oxidative addition will be preferred with non-coordinating and apolar counteranions. Indeed, $\mathrm{C} 4-\mathrm{H}$ bond activation is the dominating reaction pathway with imidazolium salts of $\mathrm{BF}_{4}{ }^{-}$ and $\mathrm{SbF}_{6}{ }^{-}$, while with imidazolium halides, $\mathrm{C}$-metallated complexes are the major products (Table 1). It should be noted that these trends account well for the results observed with iridium and osmium polyhydride species, though they do not hold for oxidative addition reactions with group 10 metals. With nickel, palladium or platinum, neither the counteranion nor the wingtip group allow for directing the metallation to the $\mathrm{C} 4$ position and only $\mathrm{C} 2$-metallated products are observed. ${ }^{33}$

Furthermore, the high affinity, in particular of low-valent iridium, ${ }^{34}$ towards olefins may play an important role in directing the regioselectivity of metallation to the $\mathrm{C} 4$ position. This affinity becomes relevant when considering the fact that the heterocyclic ligand can be fragmented into an olefinic $\mathrm{C}=\mathrm{C}$ part and a three-center-four-electron $\mathrm{NCN}$ system. ${ }^{35}$
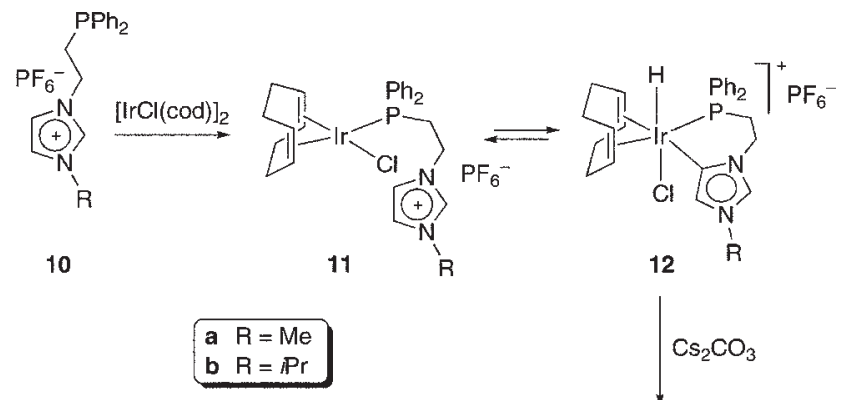

$\mathrm{Cs}_{2} \mathrm{CO}_{3}$

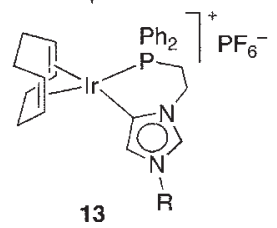

Scheme 10

Recent studies on the metallation of phosphine-functionalized imidazolium salts such as $\mathbf{1 0}$ indeed revealed that $[\operatorname{Ir}(\operatorname{cod}) \mathrm{Cl}]_{2}$ activates exclusively the $\mathrm{C} 4-\mathrm{H}$ bond without affecting the C2-H moiety (Scheme 10). ${ }^{36}$ Notably, the metallation step, that is, the transformation of the coordination complex $\mathbf{1 1}$ into the cyclometallated iridium(III) species 12, consists of an oxidative addition, as predicted for $\mathrm{C} 4-\mathrm{H}$ metallation with iridium polyhydrides. ${ }^{31}$ Reductive elimination of HX rather than $\mathrm{H}$-carbene and formation of the C4-bound carbene iridium(I) complex $\mathbf{1 3}$ has been performed in the presence of a mild base.

The metallation of $\mathbf{1 1}$ is a reversible process with equilibrium constants that are largely on the side of the cyclometallated product 12. Steric factors such as the bulk of the nitrogen substituents appear to have only a minor effect. Exchange of the anion from non-coordinating $\mathrm{PF}_{6}{ }^{-}$to potentially coordinating $\mathrm{Cl}^{-}$reduced the reaction enthalpy $\Delta H^{\circ}$ for the cyclometallation from $122 \mathrm{~kJ} \mathrm{~mol}^{-1}$ (for 11a) to $94 \mathrm{~kJ}$ $\mathrm{mol}^{-1}$, indicating that the anion is involved in the metallation process. Despite the presence of a hard chloride ion, which is supposed to promote heterolytic $\mathrm{C} 2-\mathrm{H}$ bond cleavage, ${ }^{31}$ metallation remained regioselective and took place solely at the $\mathrm{C} 4$ position. Therefore, the selective metallation of the $\mathrm{C} 4$ carbon in $\mathbf{1 1}$ must be controlled by other driving forces than those put forward for the metallation of 7, viz. bulkiness of the wingtip groups and coordination ability of the anion.

Interestingly, moving from an ethylene linker between the imidazolium and the phosphine moieties in $\mathbf{1 0}$ to a methylene linker favored $\mathrm{C}-\mathrm{H}$ bond activation considerably. The formation of the corresponding five-membered metallacycle analogous to complex $\mathbf{1 2}$ has been reported to be an irreversible process.

\section{Transmetallation}

Based on the initial results obtained from metallation of C2-substituted imidazolium salts with $\mathrm{Ag}_{2} \mathrm{O}$, a transmetallation protocol has been devised for the introduction of iridium(I) at the C4 position. ${ }^{19,21}$ The tetrasubstituted imidazolium salt $\mathbf{1 4}$ comprising an oxidation-resistant phenyl group at $\mathrm{C} 2$ has been metallated with $\operatorname{Ag}_{2} \mathrm{O}$. The intermediate, surmised to be a cationic $\left[\operatorname{Ag}(\text { carbene })_{2}\right]^{+}$complex, appeared to be unstable 


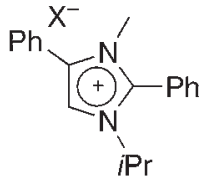

14
1) $\mathrm{Ag}_{2} \mathrm{O}$

2) $[\mathrm{IrCl}(\operatorname{cod})]_{2}$

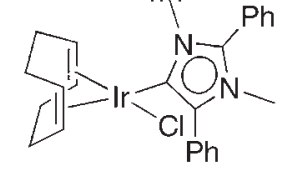

15
Scheme 11

and was transmetallated in situ by $[\mathrm{IrCl}(\operatorname{cod})]_{2}$, thus affording the stable iridium carbene complex 15 (Scheme 11).

While silver carbene complexes have been shown to be very useful carbene transfer agents for C2-bound NHC systems, due partially to their stability and facile manipulation, ${ }^{37}$ their scope appears to be significantly narrower in C4-bound carbene chemistry. Besides the restricted flexibility of introducing substituents at the $\mathrm{C} 2$ carbon (see above), the presence of substituents at the C5 position seems to be essential as well. Transmetallation reactions starting from 1,2,3-trisubstituted imidazolium salts were unsuccessful, and instead decomposition of the silver-coordinated intermediate was observed.

\section{Oxidative addition of $\mathrm{C}_{\text {imidazolium }}-\mathrm{X}$ bonds}

A further rational approach towards C4 coordination of imidazolylidenes consists of activating the $\mathrm{C} 4$ position of imidazolium salts rather than deactivating the $\mathrm{C} 2$ carbon by alkyl or aryl substitution. Thus, incorporation of a halide at C4 provides ligand precursors that can undergo oxidative addition to a low valent metal center. Installation of an iodide at the C4 position starting from 4-iodoimidazole $\mathbf{1 6}$ has recently been demonstrated to be a useful strategy for preparing the palladium complexes $\mathbf{1 8}$ comprising a chelating C4-coordinated carbene ligand (Scheme 12). ${ }^{38}$ Variable-temperature analyses indicated that the $\mathrm{C} 4$-bonding mode is thermostable up to $100{ }^{\circ} \mathrm{C}$ and no rearrangement to thepresumably thermodynamically more stable - C2-bound isomer has been observed. Clearly, oxidative addition to lowvalent metal precursors different from palladium(0) are required to evaluate whether this metallation methodology is of potential general scope.

It is noteworthy from a synthetic perspective that this methodology affords complexes in which the relatively acidic C2-bound proton is still available for further manipulations. Dimetallic systems with the heterocycle adopting a bridging carbene-carbanion ditopic ligand function have been produced recently, albeit starting from C2-metallated carbenes. ${ }^{39}$

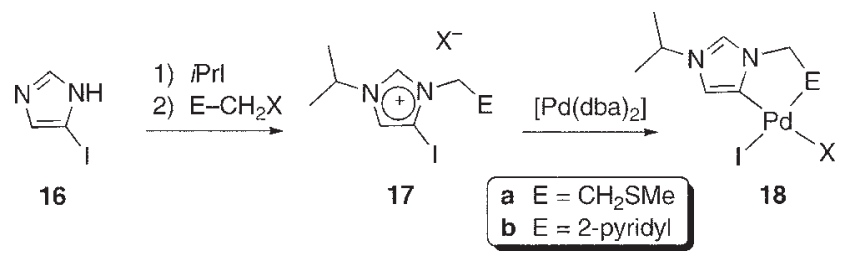

Scheme 12

\section{Structural and electronic impact of $\mathrm{C} 4$ bonding}

\section{Steric considerations}

While many principles deduced for C2-bound imidazolylidenes also hold for their C4-bound analogues, ${ }^{40}$ in C4-bound carbenes the $\alpha^{\prime}$-positioned nucleus, viz. the C5 carbon, can be unsubstituted. In such complexes, only the group attached to N3 impinges into the metal coordination sphere. This fact has a distinct impact on the orientation of the carbene ligand relative to the coordination geometry of the metal center. Crystallographic analyses of several square-planar dicarbene palladium(II) complexes reveals that the torsion angle between the heterocyclic carbene ligand and the metal coordination plane is typically around $20-30^{\circ}$ in C4-bound dicarbenes, while in the corresponding $\mathrm{C} 2$-bound dicarbenes, ${ }^{29}$ the additional wingtip group in the $\alpha^{\prime}$ position of the metal-bound carbon twists the ligand about $35-45^{\circ}$ out of the metal coordination plane (Fig. 1). As a consequence, the C4-bound carbenes are more appropriately oriented for exploiting ligand-metal $\pi$ (back)bonding interactions and ligand tuning may hence become more efficient. In addition, the reduced steric bulk around the metal coordination sphere in C4-bound carbenes is expected to lower the shielding of the metalcarbene bond. Easier accessibility of the metal center should increase the sensitivity of the $\mathrm{M}-\mathrm{C}$ bond, and simultaneously, this may facilitate the (transient) bonding of larger substrates, for example for catalytic transformations.

\section{Electronic consequences}

Different tools have been used to assess the electronic implications of carbene C4-bonding and they consistently indicate that these abnormal carbenes are stronger donors than their C2-bound analogues. ${ }^{41}$ While crystallographic analysis indicates that the metal-carbene bond lengths are dominated by other effects than the bond strength (such as steric repulsion of wingtip groups, chelate bite angle, etc.), the metal-X bond trans to the carbene may be more diagnostic. Substantial differences in metal-halide bond lengths have been noted when comparing the sterically identical complexes 19 and 20 (Fig. 2(a)). ${ }^{25}$ Superposition of the X-ray structures of the complexes (Fig. 2(b)) reveals that the palladium(dicarbene) parts are virtually identical. The most significant difference concerns the position of the halide anions. The palladium-chloride bond in the C4-bound dicarbene complex 19 is considerably elongated (average $\mathrm{Pd}-\mathrm{Cl} 2.404(4) \AA$ ) as

a)

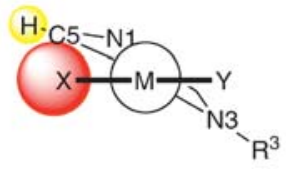

b)

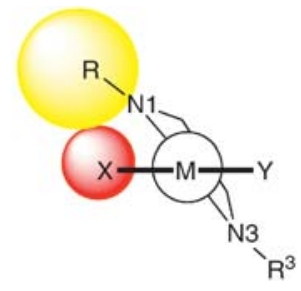

Fig. 1 Newman-projection of a metal-carbene fragment along the $\mathrm{M}-\mathrm{C}$ bond in a square-planar complex; (a) Reduced steric repulsion in C4-bound carbenes containing a proton at the $\alpha$ carbon (denoted C5) as compared to (b) C2-bound carbenes with relatively bulky substituents on the $\alpha$-positioned nitrogen N1. 
a)
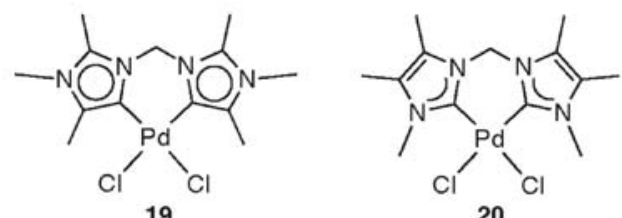

b)

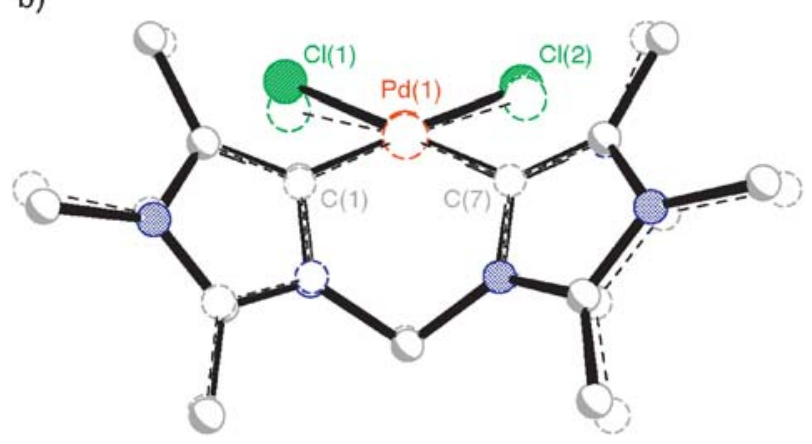

Fig. 2 (a) Schematic representation of the isostructural complexes 19 and $\mathbf{2 0}$ and (b) superposition of ball-and-stick models of the structures as determined by X-ray crystallography (19 solid lines, $\mathbf{2 0}$ dashed).

compared to complex $\mathbf{2 0}$ containing $\mathrm{C} 2$-bound carbene ligands (average $\mathrm{Pd}-\mathrm{Cl} 2.357(2) \AA$ ). This difference reflects the larger trans influence of C4-bound carbenes.

The CO stretch frequencies in square-planar iridium(I) and rhodium(I) dicarbonyl complexes provides another useful probe for the donor strength of ligands and allows the ligands to be classified according to Tolman electronic parameters (TEPs). ${ }^{42}$ The currently available data for C4-bound carbene complexes of the type $\left[\operatorname{IrCl}(\mathrm{CO})_{2} \mathrm{~L}\right]$ are compiled in Fig. 3(a), related $\mathrm{C} 2$-bound carbene complexes and phosphines are shown in Fig. 3(b). Accordingly, C4-bound carbenes in complexes 21-24 induce a considerably lower stretch frequency $\left(\nu_{\text {av }}(\mathrm{CO})\right.$ 1999-2015 $\left.\mathrm{cm}^{-1}\right)$ than sterically similar C2-bound carbenes in 25-27 $\left(\nu_{\mathrm{av}}(\mathrm{CO}) 2017-2020 \mathrm{~cm}^{-1}\right),{ }^{43}$ which in turn are lower than the most basic alkyl phosphines (e.g. $\nu_{\text {av }}(\mathrm{CO})$ $2028 \mathrm{~cm}^{-1}$ for $\mathrm{L}=\mathrm{PCy}_{3}$ in 28). The electron-donor ability of C4-bound carbenes seems to be inductively tunable over a broader range than the corresponding $\mathrm{C} 2$ systems. Functionalization of the benzylic substituent in complex 22 with electron-withdrawing groups $\left(\mathrm{R}=\mathrm{CF}_{3}\right.$ or $\left.\mathrm{F}\right)$ shifts the average CO stretch frequency up to 2017 and $2020 \mathrm{~cm}^{-1}$, respectively. This is the typical range for iridium carbonyl complexes containing less strongly donating C2-bound carbenes.

The vibrational differences in the related rhodium(I) complexes 29-31 appeared to be less pronounced. Clearly, more data of C4-bound complexes are required in order to deduce significant trends.

In depth information on the electronic configuration of the metal center in carbene complexes has been obtained by X-ray photoelectron spectroscopy (XPS). When comparing the C4-bound dicarbene complex $\mathbf{5 a}$ and its similarly substituted a)<smiles></smiles>

21

$v_{\mathrm{av}}(\mathrm{CO})=2003 \mathrm{~cm}^{-1}$

(ref. 19)

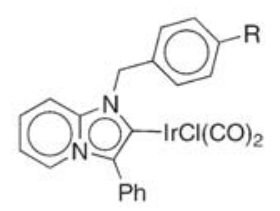

22

$v_{\text {av }}(\mathrm{CO})=1999 \mathrm{~cm}^{-1}(\mathrm{R}=\mathrm{H})$

$v_{\text {av }}(\mathrm{CO})=2008 \mathrm{~cm}^{-1}(\mathrm{R}=\mathrm{OMe})$

$v_{\mathrm{av}}(\mathrm{CO})=2017 \mathrm{~cm}^{-1}\left(\mathrm{R}=\mathrm{CF}_{3}\right)$

$v_{\mathrm{av}}(\mathrm{CO})=2020 \mathrm{~cm}^{-1}(\mathrm{R}=\mathrm{F})$

(ref. 21)

b)

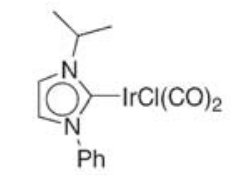

25

$v_{\text {av }}(\mathrm{CO})=2019 \mathrm{~cm}^{-1}$

(ref. 19)

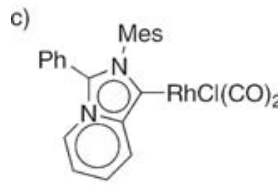

29

$v_{\text {av }}(\mathrm{CO})=2032 \mathrm{~cm}^{-1}$

(ref. 20)

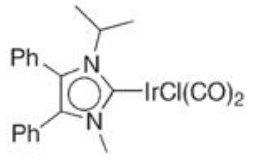

26

$v_{\text {av }}(\mathrm{CO})=2017 \mathrm{~cm}^{-1}$

(ref. 19)

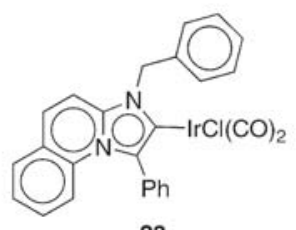

23

$v_{\text {av }}(C O)=2015 \mathrm{~cm}^{-1}$

(ref. 21)<smiles></smiles>

24

$v_{\text {av }}(C O)=2006 \mathrm{~cm}^{-1}$

(ref. 21)<smiles>CCCCCCCCCCC(=O)OCc1ccccc1</smiles>

27 $v_{\text {av }}(C O)=2020 \mathrm{~cm}^{-1}$

(ref. 43)

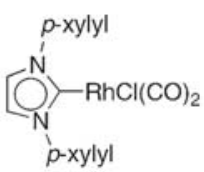

31

$v_{\text {av }}(C O)=2036 \mathrm{~cm}^{-1}$

(ref. 43)

Fig. 3 Collection of IR data on (a) complexes of the type $\operatorname{IrCl}(\mathrm{CO})_{2} \mathrm{~L}$ with $\mathrm{L}=\mathrm{C} 4$-bound carbene and (b) comparative data of $\mathrm{C} 2$-bound carbenes and basic phosphines; $\mathrm{Cy}=$ cyclohexyl); (c) data available on corresponding complexes $\mathrm{RhCl}(\mathrm{CO})_{2} \mathrm{~L}$. 


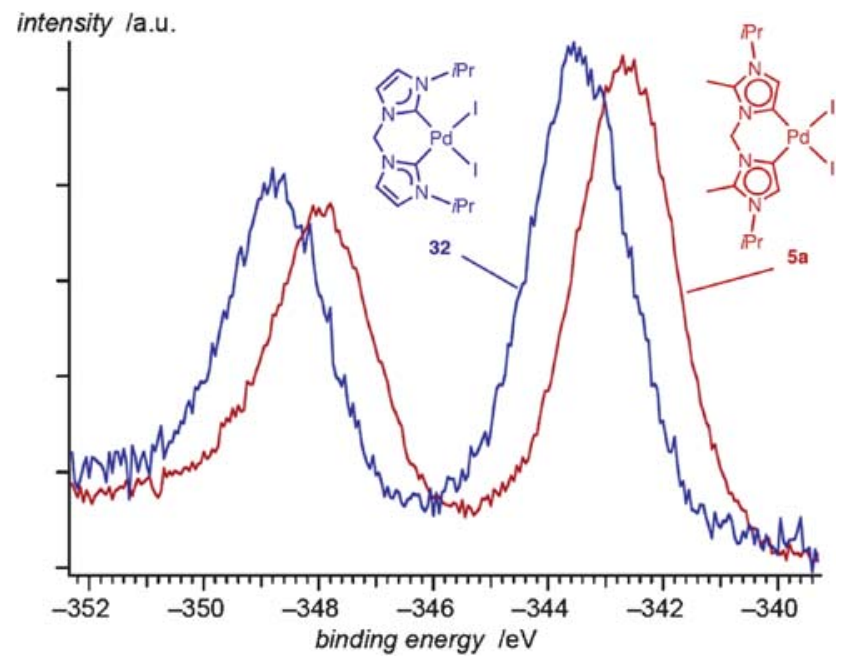

Fig. 4 Section of the overlayered XPS spectra of $\mathbf{5 a}$ and $\mathbf{3 2}$.

counterpart 32, a diagnostic $0.6 \mathrm{eV}$ shift of the palladium $3 \mathrm{~d}$ electron binding energies has been observed (Fig. 4). ${ }^{22}$ The weaker electron bonding in $\mathbf{5} \mathbf{a}$ reflects the stronger donor ability of the C4-bound carbene. Notably, similar binding energy differences have been measured for the sterically identical complexes 19 and 20 (Fig. 2(a)), ${ }^{25}$ indicating that they originate indeed from electronic factors while steric contributions (including mutual arrangement of orbitals) are relatively small.

\section{Bonding considerations}

The location of the heteroatoms in C4-bound carbenes implies that the metal-bound carbon has a higher electron density than the metal-bound carbon in Arduengo-type NHC complexes. This can be rationalized by the lower inductive electron-withdrawing effect of the $\alpha$-carbon in C4-bound carbenes as opposed to an $\alpha$-nitrogen in $\mathrm{C} 2$-bound carbenes. In addition, the steric and electronic effects noted in the previous sections combined with preliminary theoretical investigations suggest that the C4-bound carbene ligand can be divided in a first approximation into a three-center-four-electron $\mathrm{NCN}$ fragment and an olefinic $\mathrm{C}=\mathrm{C}$ part, similar to $\mathrm{C} 2$-bound carbenes (Scheme 13). ${ }^{35}$

Such a limiting resonance structure for C4-bound carbene complexes may be energetically more favored due to an improved charge separation as opposed to C2-bound
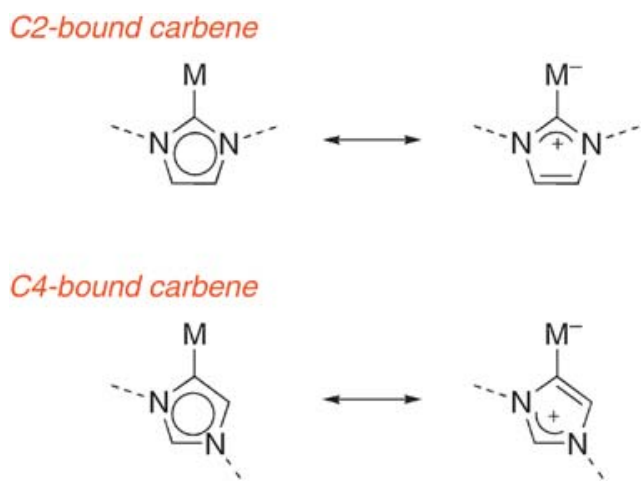

Scheme 13 carbenes, where both negative and positive formal charges are part of the same fragment. According to this model, a C4-bound carbene could be regarded as an anionic vinyl ligand with an appended amidinium moiety for intramolecular charge compensation. Such vinyl-type formally anionic ligand bonding might provide another rational for the very high donor power of C4-bound carbenes in addition to the inductive effects noted previously.

\section{Impact on reactivity: towards new catalytic applications}

The exceptionally strong donor ability of C4-bound carbenes is expected to have a significant impact on catalysis and on reactivity properties of coordinated metal centers. While up to now, most studies on C4-bound carbenes have concentrated on developing synthetic protocols and on assessing the electronic and structural properties imposed by this ligand, results on the activity of $\mathrm{C} 4$-bound metal complexes are still relatively scarce. Despite the limited results available, evidence for the beneficial impact of the C4-bonding mode of carbenes has been demonstrated in reactions that are not accessible by using other ligands.

\section{Stoichiometric reactions}

The palladium dicarbene complexes 5 were found to react with $\mathrm{Ag}^{+}$ions to give, after halide exchange, the adduct 33 comprising remarkably strong Pd $\cdots A g$ interaction (Scheme 14). ${ }^{22}$ Single-crystal structure analysis of the adduct $33(\mathrm{R}=i \mathrm{Pr})$ revealed a Pd-Ag distance of 2.8701(6) $\AA$, which is one of the shortest contacts known so far. ${ }^{44}$ The propensity of the Pd(dicarbene) unit to bind effectively to a Lewis acid has been used to underline the high electron density of the palladium center in a C4-bound dicarbene ligand environment. Atomic absorption spectroscopy of amorphous material indicated a $1: 1$ ratio of palladium and silver, hence suggesting that adduct formation is the major reaction pathway in this reaction. In line with the notion of the formally dicationic palladium center as Lewis base in these adducts, the silver cation can be removed from the palladium coordination sphere by using donor solvents such as $\mathrm{MeOH}$ or DMSO, which appear to successfully compete with the Pd center for silver coordination. Accordingly, best yields of the bis(solvento) complexes $\mathbf{3 4}$ are obtained when the $\mathrm{Ag}^{+}$mediated halide abstraction is performed with 3 mol equiv. of

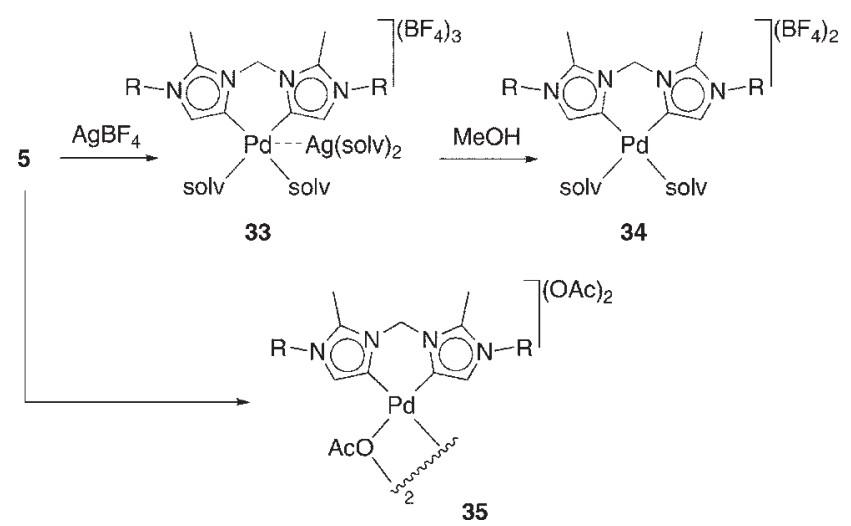

Scheme 14 


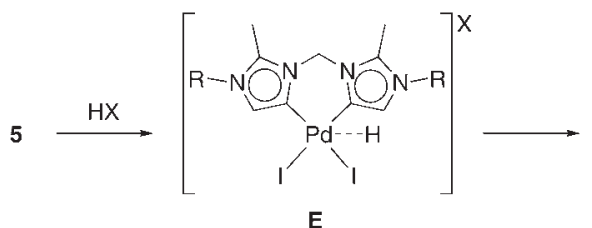

Scheme 15

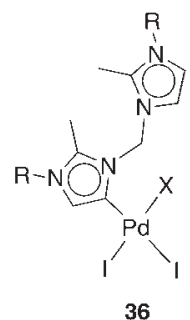

36
$\mathrm{Ag}^{+}$ions followed by a purification process that includes trituration from $\mathrm{MeOH}$.

Adduct formation as in $\mathbf{3 3}$ can be circumvented when using silver salts containing anions that coordinate better than $\mathrm{BF}_{4}{ }^{-}$. The reaction of 5 with $\mathrm{Ag}(\mathrm{OAc})$ leads to the formation of the dimer 35 (Scheme 14). In this complex, charge compensation seems to occur via relatively short Pd..Pd contacts. ${ }^{45}$

An adduct related to $\mathbf{3 3}$ may also be formed when reacting the electron-rich complex $\mathbf{3 2}$ with Brønsted acids. In the presence of strong acids such as $\mathrm{H}_{2} \mathrm{SO}_{4}$, a rapid reaction takes place that leads to palladium-carbon bond cleavage and formation of the monocarbene complex $\mathbf{3 6}$ comprising a dangling imidazolium residue (Scheme 15). ${ }^{24}$ Similar to $\mathrm{Ag}^{+}$-adduct formation, the proton may be trapped by the high-lying and basic $\mathrm{d}_{z^{2}}$ orbital of palladium, thus providing intermediate E. Subsequent hydrogen migration from palladium to the $\mathrm{C} 4$ carbon and concomitant $\mathrm{Pd}-\mathrm{C}$ bond cleavage then produces an imidazolium fragment, and eventually $\mathbf{3 6}$. An alternative process may be conceivable, in which the proton is captured directly by $\mathrm{C} 4$ as a consequence of the limited ortho shielding of the $\mathrm{Pd}-\mathrm{C}$ bond. The inertness of complex 36 towards further acidolysis suggests, however, that the electron density at the metal center plays a crucial role. Mechanistic studies would be highly desirable for elucidating the nature of the metal-bound hydrogen in the postulated intermediate $\mathbf{E}$, since this intermediate can be formulated either as a $\mathrm{Pd}^{\mathrm{IV}}$-hydride species resulting from oxidative addition or as a $\mathrm{Pd}^{\mathrm{II}}$-proton adduct.

\section{Catalytic applications}

Given the high basicity of the metal center in a C4-bound carbene setting, reactions involving oxidative addition sequences as key steps are most likely to benefit from these strongly donating ligands. We have therefore probed the catalytic activity of the $\mathrm{Pd}$ (dicarbene) complex 34 (Scheme 14) in the direct hydrogenation of alkenes (Scheme 16), ${ }^{22}$ which involves as a key step the activation of dihydrogen.

Complexes 34 display considerable catalytic activity in the hydrogenation of terminal olefins (styrene) and cis-olefins (cyclooctene). Notably, these complexes show a substantially

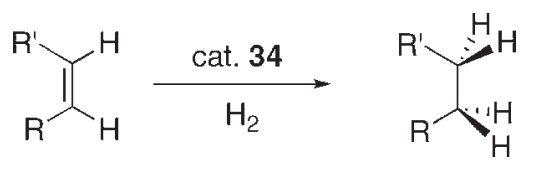

Scheme 16 better performance than their C2-bound analogues and allow for hydrogenation under mild conditions, that is, at room temperature and atmospheric $\mathrm{H}_{2}$ pressure. In EtOH as solvent, the reaction is complete within $4 \mathrm{~h}$ when using the C4-bound dicarbene complex 34 (1 mol\% catalyst loading), while less than $20 \%$ conversion were obtained with the corresponding C2-bound analogue under otherwise identical conditions. Solvent screening revealed that in apolar solvents such as toluene and THF, catalytic rates are slower, presumably due to the limited solubility of $\mathbf{3 4}$ in these media. Likewise, no conversions were observed when catalytic reactions were performed in very polar solvents (e.g. DMSO, DMF). Apparently, strongly coordinating solvents effectively compete with olefins for binding to the metal center and hence result in catalyst deactivation.

While mechanistic studies of this reaction are still ongoing, we assume that a key function of the C4-bound dicarbene ligand consists of providing the required electron density to promote oxidative $\mathrm{H}_{2}$ addition to the palladium center. Apparently, less strong donors such as C2-bound dicarbenes are not able to sufficiently increase the electron density at the metal. Further mechanistic studies are warranted, in particular in order to address whether hydrogenation under these mildly reducing conditions proceeds homogeneously or via metal reduction and subsequent dissociation to give a heterogeneous palladium species as the active catalyst.

Rhodium complexes comprising C4-bound dicarbene ligands such as 6 (Scheme 8) effectively catalyze the transfer hydrogenation of ketones from $i \mathrm{PrOH}$ as dihydrogen source (Scheme 17, Table 2). ${ }^{23}$ The substituents on the remote nitrogen and on the $\mathrm{C} 2$ carbon have only marginal influence on the catalytic activity of the rhodium center. However, the bonding mode of the carbene is crucial. The C2-bound analogue 36 essentially fails to catalyze transfer hydrogenation. This has been discussed in terms of electron density at the metal center, which appears to positively correlate with catalytic activity. In line with this hypothesis, replacing the iodide ligands in $\mathbf{6}$ by stronger donating chlorides $(\mathrm{X}=\mathrm{Cl})$ doubles the initial turnover frequency of the catalyst. Deuterium labeling experiments revealed a selective transfer of the carbinol hydrogen of $i \mathrm{PrOH}$ to the carbon of the ketone substrate, ${ }^{46}$ which is indicative for a monohydride mechanism. ${ }^{47}$ The remarkably high electron density at the rhodium center in $\mathbf{6}$ and its dichloride analogue has been suggested to accelerate $\beta$ hydrogen elimination of the isopropoxide intermediate as well as product release, thus providing high turnover rates.

The mixed complex 37a containing both a C2-bound and a C4-bound carbene ligand catalyzes the coupling of aryl boronic acids with aryl chlorides (Suzuki-Miyaura cross-coupling;

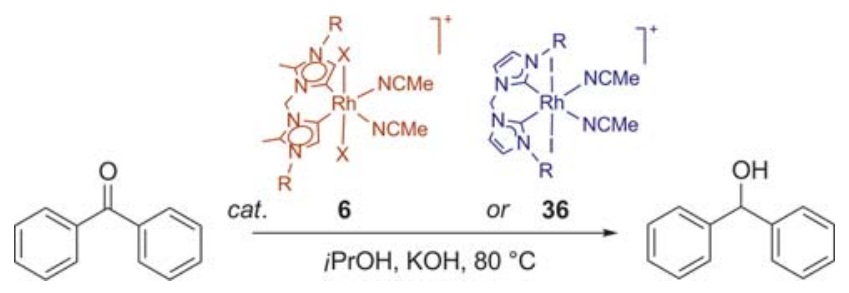

Scheme 17 
Table 2 Catalytic activity of complexes $\mathbf{6}$ and $\mathbf{3 6}$ in transfer hydrogenation of benzophenone (Scheme 17)

\begin{tabular}{lllll}
\hline Catalyst & $\mathrm{R}$ & $\mathrm{X}$ & $\begin{array}{l}\text { Conv. } \\
\text { after } 2 \mathrm{~h}(\%)\end{array}$ & $\mathrm{TOF}_{50}{ }^{a} / \mathrm{h}^{-1}$ \\
\hline $\mathbf{3 6}$ & $n \mathrm{Bu}$ & $\mathrm{I}$ & 17 & n.a. \\
$\mathbf{6}$ & $n \mathrm{Bu}$ & $\mathrm{I}$ & 97 & 111 \\
$\mathbf{6}$ & $i \mathrm{Pr}$ & $\mathrm{I}$ & 87 & 94 \\
$\mathbf{6}$ & $\mathrm{Mes}$ & $\mathrm{I}$ & 91 & 121 \\
$\mathbf{6}$ & $\mathrm{Mes}$ & $\mathrm{Cl}$ & 95 & 300
\end{tabular}

${ }^{a}$ Turnover frequency as mol (mol catalyst $\left.\mathrm{h}\right)^{-1}$ at $50 \%$ conversion; n.a. $=$ not available.

Scheme $\left.18, \mathrm{X}=\mathrm{B}(\mathrm{OH})_{2}\right) .^{48}$ The catalytic activity is nearly doubled when the catalyst is formed in situ from $\left[\mathrm{Pd}(\mathrm{OAc})_{2}\right]$, the imidazolium chloride and $\mathrm{Cs}_{2} \mathrm{CO}_{3}$. This is remarkable since identical conditions were used for the preparation of the homoleptic complex 38a, which is an essentially inactive catalyst. Apparently, under catalytic conditions the formation of 38a is substantially suppressed. In contrast, related intramolecular arylation of aryl chlorides via $\mathrm{C}-\mathrm{H}$ bond activation (Scheme 18, $\mathrm{X}=\mathrm{H}$ ) proceeded better when using the C2-bound complex 38b rather than the mixed analogue $\mathbf{3 7 b} .^{49}$

The presence of a C4-bound carbene in complex 37a also enhanced the activity of the palladium center in catalyzing the olefination of aryl bromides (Heck-Mizoroki crosscoupling) ${ }^{48}$ At relatively high temperatures $\left(120{ }^{\circ} \mathrm{C}\right)$, the mixed complex 37a was found to be more active than the in situ prepared catalyst, while complex 38a with two C2-bound carbenes did not show any activity at all.

Notably, complexes $\mathbf{5}$ or $\mathbf{3 4}$ featuring two chelating C4-bound carbene ligands failed to catalyze Suzuki and Heck-type cross-couplings (for example $44 \%$ conversion of 4-bromoanisole to 4-methoxybiphenyl in DMA at $130{ }^{\circ} \mathrm{C}$ at $1 \%$ catalyst loading). ${ }^{50}$ Presumably this is a direct consequence of the unique steric and electronic implications of the dicarbene ligand. The rigid $85( \pm 3)^{\circ}$ chelate bite angle strongly disfavors the reduction of the palladium(II) center, as it fails to accommodate an eventually formed palladium( $(0)$ intermediate in a trigonal-planar coordination environment (ideally $120^{\circ}$ ligand angles). In addition, the strong donor ability of the two C4-bound carbenes makes metal reduction a highly unlikely event and sets the stage rather for an oxidative addition. As a consequence, the low activity observed with complexes $\mathbf{5}$ and 34 probably originates from traces of de-coordinated palladium due to partial complex decomposition.

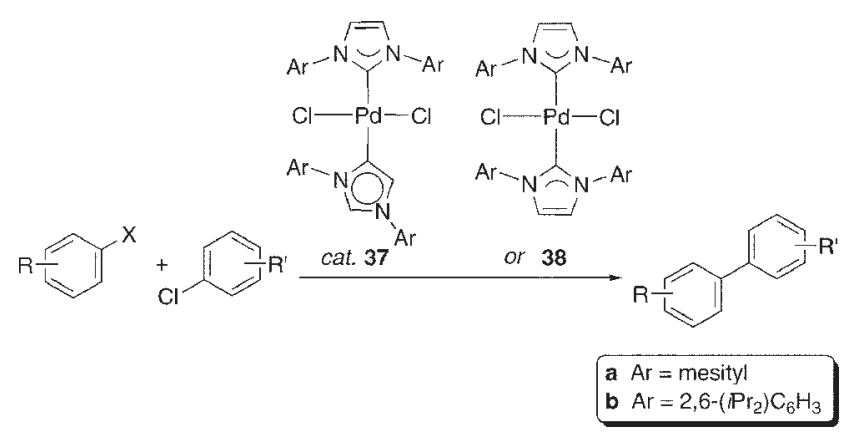

Scheme 18

\section{Conclusions}

The development of efficient catalysts for the activation of strong bonds correlates remarkably well with the discovery of strong donor ligands. Major advances have been achieved when moving from triaryl phosphines to trialkyl phosphines, and later to C2-bound heterocyclic carbenes. All experimental and theoretical evidences now suggest that $\mathrm{C} 4$-bound carbene ligands are even stronger ligands that substantially exceed $\mathrm{C} 2$-bound carbenes. These unique ligand properties have been exploited by developing useful catalytic applications where electron-rich metal centers play a key role. When taking into account the vast possibilities for ligand tuning and the promising initial achievements in activating unreactive bonds, C4-bound carbenes have an enormous potential for further catalysts development and also for application as components in optics and electronics. Theoretical studies on the fundamental bonding principles in such C4-bound carbene ligands and metal complexes are certainly warranted, in particular for devising rational catalyst design and optimization methods.

\section{Acknowledgements}

The author wishes to thank his current and former co-workers for their enthusiasm and dedication in developing this exciting field of research, and Antonia Neels, Andreas Ehlers, and Claude Daul for fruitful collaborations. M. A. thanks the Royal Society of New Zealand (ISAT Linkages Fund) for financial support and the Department of Chemistry (University of Otago) and Sally Brooker for hosting a sabbatical visit during manuscript preparation. Our research in carbene chemistry has been substantially supported by the Swiss National Science Foundation, ERA-net Chemistry, Cost Action D40 and Sasol Ltd. M. A. thanks the Alfred Werner Foundation for an Assistant Professorship.

\section{Notes and references}

1 T. Sajoto, P. I. Djurovich, A. Tamayo, M. Yousufuddin, R. Bau, M. E. Thompson, R. J. Holmes and S. R. Forrest, Inorg. Chem., 2005, 44, 7992.

2 (a) D. M. Khramov, A. J. Boydston and C. W. Bielawski, Angew. Chem., Int. Ed., 2006, 45, 6186; (b) L. Mercs, A. Neels and M. Albrecht, submitted.

3 (a) W. A. Herrmann, Angew. Chem., Int. Ed., 2002, 41, 1290; (b) NHeterocyclic Carbenes in Synthesis, ed. S. P. Nolan, Wiley-VCH, Weinheim, 2006; (c) F. E. Hahn and M. C. Jahnke, Angew. Chem., Int. Ed., 2008, 47, 3122.

4 T. M. Trnka and R. H. Grubbs, Acc. Chem. Res., 2001, 34, 18.

5 (a) E. A. B. Kantchev, C. J. O'Brien and M. G. Organ, Angew. Chem., Int. Ed., 2007, 46, 2768; (b) C. J. O’Brien, E. A. B. Kantchev, C. Valente, N. Hadei, G. A. Chass, A. Lough, A. C. Hopkins and M. G. Organ, Chem.-Eur. J., 2006, 12, 4743; (c) O. Navarro, N. Marion, J. Mei and S. P. Nolan, Chem.-Eur. J., 2006, 12, 5142 .

6 For examples, see: (a) S. Nanchen and A. Pfaltz, Chem.-Eur. J., 2006, 12, 4550; (b) S. Burling, B. M. Paine, D. Nama, V. S. Brown, M. F. Mahon, T. J. Prior, P. S. Pregosin, M. K. Whittlesey and J. M. J. Williams, J. Am. Chem. Soc., 2007, 129, 1987.

7 S. Gründemann, A. Kovacevic, M. Albrecht, J. W. Faller and R. H. Crabtree, Chem. Commun., 2001, 2274.

8 The class of abnormal carbenes, i.e. carbenes for which no neutral canonical resonance form can be drawn, is not restricted to C4-bound imidazolylidenes and includes, for example, also 4-pyrazolylidenes, pioneered by Huynh, and 3-pyridylidenes. For leading 
references, see: (a) Y. Han and H. V. Huynh, Chem. Commun., 2007, 1089; (b) Y. Han, H. V. Huynh and G. K. Tan, Organometallics, 2007, 26, 6581. For complexes comprising abnormal pyridylidene ligands, see: ; (c) K. Isobe, Y. Nakamura, T. Miwa and S. Kawaguchi, Bull. Chem. Soc. Jpn., 1987, 60, 149; (d) P. Casten, F. Dahan, S. Wimmer and F. L. Wimmer, J. Chem. Soc., Dalton Trans., 1990, 2971; (e) S. Wimmer and F. L. Wimmer, J. Chem. Soc., Dalton Trans., 1994, 879; (f) T. Koizumi, T. Tomon and K. Tanaka, Organometallics, 2003, 22, 970.

9 H. G. Raubenheimer and S. J. Cronje, Dalton Trans., 2008, 1265.

10 (a) S. Sole, H. Gornitzka, W. W. Schoeller, D. Bourissou and G. Bertrand, Science, 2001, 292, 1901; (b) V. Lavallo, Y. Canac, C. Präsang, B. Donnadieu and G. Bertrand, Angew. Chem., Int. Ed., 2005, 44, 5705; (c) V. Lavallo, Y. Canac, A. DeHope, B. Donnadieu and G. Bertrand, Angew. Chem., Int. Ed., 2005, 44, 7236.

11 A. J. Arduengo, R. L. Harlow and M. Kline, J. Am. Chem. Soc., 1991, 113, 361.

12 (a) G. Sini, O. Eisenstein and R. H. Crabtree, Inorg. Chem., 2002, 41, 602; (b) R. Tonner, G. Heydenrych and G. Frenking, Chem.-Asian J., 2007, 2, 1555.

13 A. M. Magill and B. F. Yates, Aust. J. Chem., 2004, 57, 1205.

14 M. K. Denk and J. M. Rodezno, J. Organomet. Chem., 2001, 617, 737.

15 A. J. Arduengo, F. Davidson, H. V. R. Dias, J. R. Goerlich, D. Khasnis, W. J. Marshall and T. K. Prakasha, J. Am. Chem. Soc., 1997, 119, 742.

16 (a) X. Hu, I. Castro-Rodriguez and K. Meyer, Organometallics, 2003, 22, 3016; (b) A. A. Danopoulos, N. Tsoureas, J. A. Wright and M. E. Light, Organometallics, 2004, 23, 166; (c) N. Stylianides, A. A. Danopoulos and N. Tsoureas, J. Organomet. Chem., 2005, 690, 5948; (d) C. E. Ellul, M. F. Mahon, O. Saker and M. K. Whittlesey, Angew. Chem., Int. Ed., 2007, 46, 6343.

17 P. L. Arnold and S. Pearson, Coord. Chem. Rev., 2007, 251, 596.

18 D. Bacciu, K. J. Cavell, I. A. Fallis and L.-L. Ooi, Angew. Chem., Int. Ed., 2005, 44, 5282.

19 A. R. Chianese, A. Kovacevic, B. M. Zeglis, J. W. Faller and R. H. Crabtree, Organometallics, 2004, 23, 2461.

20 M. Alcarazo, S. J. Roseblade, A. R. Cowley, R. Fernandez, J. M. Brown and J. M. Lassaletta, J. Am. Chem. Soc., 2005, 127, 3290.

21 G. Song, Y. Zhang and X. Li, Organometallics, 2008, 27, 1936.

22 M. Heckenroth, E. Kluser, A. Neels and M. Albrecht, Angew. Chem., Int. Ed., 2007, 46, 6293.

23 L. Yang, A. Krüger, A. Neels and M. Albrecht, Organometallics, 2008, 27, 3161

24 M. Heckenroth, A. Neels and M. Albrecht, submitted.

25 M. Heckenroth and M. Albrecht, unpublished work.

26 A. R. Chianese, B. M. Zeglis and R. H. Crabtree, Chem. Commun., 2004, 2176.

27 A. M. Voutchkova, M. Feliz, E. Clot, O. Eisenstein and R. H. Crabtree, J. Am. Chem. Soc., 2007, 129, 12834.

28 M. Viciano, M. Feliz, R. Corberan, J. A. Mata, E. Clot and E. Peris, Organometallics, 2007, 26, 5304.

29 (a) W. A. Herrmann, C.-P. Reisinger and M. Spiegler, J. Organomet. Chem., 1998, 557, 93; (b) W. A. Herrmann, J. Schwarz and M. G. Gardiner, Organometallics, 1999, 18, 4082; (c) M. Heckenroth, A. Neels, H. Stoeckli-Evans and M. Albrecht, Inorg. Chim. Acta, 2006, 359, 1929 .
30 Notably, $\mathrm{C}-\mathrm{H}$ bond oxidative addition at the $\mathrm{C} 4$ position requires more forcing conditions when compared with $\mathrm{C} 2-\mathrm{H}$ oxidative addition, indicating that the $\mathrm{C} 2-\mathrm{H}$ is more activated than the C4-H bond. For details, see ref. 18.

31 (a) S. Gründemann, A. Kovacevic, M. Albrecht, J. W. Faller and R. H. Crabtree, J. Am. Chem. Soc., 2002, 124, 10473; (b) L. N. Appelhans, D. Zuccaccia, A. Kovacevic, A. R. Chianese, J. R. Miecznikowski, A. Macchioni, E. Clot, O. Eisenstein and R. H. Crabtree, J. Am. Chem. Soc., 2005, 127, 16299.

32 (a) M. Baya, B. Eguillor, M. A. Esteruelas, M. Loivan and E. Onate, Organometallics, 2007, 26, 6556; (b) B. Eguillor, M. A. Esteruelas, M. Olivan and M. Puerta, Organometallics, 2008, 27, 445.

33 K. J. Cavell and D. S. McGuinness, Coord. Chem. Rev., 2004, 248, 671.

34 R. Crabtree, Acc. Chem. Res., 1979, 12, 331.

35 E. F. Penka, C. W. Schläpfer, M. Atanasov, M. Albrecht and C. Daul, J. Organomet. Chem., 2007, 692, 5709.

36 G. Song, X. Wang, Y. Li and X. Li, Organometallics, 2008, 27, 1187.

37 J. C. Garrison and W. J. Youngs, Chem. Rev., 2005, 105, 3978.

38 E. Kluser, A. Neels and M. Albrecht, Chem. Commun., 2006, 4495.

39 (a) P. L. Arnold and S. T. Liddle, Organometallics, 2006, 25, 1485; (b) U. J. Schele, S. Dechert and F. Meyer, Chem.-Eur. J., 2008, 14, 5112 .

40 (a) D. Bourissou, O. Guerret, F. Gabbai and G. Bertrand, Chem. Rev., 2000, 100, 39; (b) S. Diez-Gonzalez and S. P. Nolan, Coord. Chem. Rev., 2007, 251, 874.

41 For other exceptionally strong donor ligands, see: $(a) \mathrm{K}$. Denk, P. Sirsch and W. A. Herrmann, J. Organomet. Chem., 2002, 649, 219; (b) P. Bazinet, G. P. A. Yap and D. S. Richeson, J. Am. Chem. Soc., 2003, 125, 13314; (c) M. Mayr, K. Wurst, K.-H. Ongania and M. R. Buchmeiser, Chem.-Eur. J., 2004, 10, 1256.

42 (a) W. Strohmeier and F. J. Müller, Chem. Ber., 1967, 100, 2812; (b) C. A. Tolman, Chem. Rev., 1977, 77, 313.

43 A. R. Chianese, X. Li, M. C. Janzen, J. W. Faller and R. H. Crabtree, Organometallics, 2003, 22, 1663.

44 Only one complex features shorter Pd..Ag interactions, see: (a) Y. Liu, K. H. Lee, J. J. Vittal and T. S. A. Hor, J. Chem. Soc., Dalton Trans., 2002, 2747; (b) for an overview, see: J. Forniés and A. Martin, in Metal Clusters in Chemistry, ed. P. Braunstein, L. A. Oro and P. R. Raithby, Wiley-VCH, Weinheim, 1999, vol. 1, p. 417.

45 The Pd...Pd distance in complex 35 is 2.9441(6) $\AA$ and hence shorter than the sum of the van der Waals radii $(3.30 \AA)$. In a related dimeric complex featuring $\mathrm{C} 2$-bound dicarbene ligands, the $\mathrm{Pd} \cdots \mathrm{Pd}$ distance is $3.168 \AA$ and hence substantially longer than in $\mathbf{3 5}$, see: J. C. Slootweg and P. Chen, Organometallics, 2006, 25, 5863.

46 A. Krüger, L. Yang, A. Neels and M. Albrecht, XVI International Symposium on Homogeneous Catalysis, Abstract Nr. 234.

47 (a) O. Pamies and J.-E. Bäckvall, Chem.-Eur. J., 2001, 7, 5052; (b) J. S. M. Samec, J.-E. Bäckvall, P. G. Andersson and P. Brandt, Chem. Soc. Rev., 2006, 35, 237.

48 H. Lebel, M. K. Janes, A. B. Charette and S. P. Nolan, J. Am. Chem. Soc., 2004, 126, 5046.

49 L. Campeau, P. Thansandote and K. Fagnou, Org. Lett., 2005, 7, 1857.

50 M. Heckenroth and M. Albrecht, Chimia, 2008, 62, 253. 